Sandeep Kate ${ }^{1}$, PhD-student

DOI: https://doi.org/10.20535/0203-3771402020248758

\title{
STATE OF RESEARCH AND DEVELOPMENT OF SMALL SPACECRAFT WITH OPTICAL COMMUNICATION
}

Ua Розглянуто сучасний стан науково-технічних досліджень та розробок малих космічних апаратів із використанням оптичних систем зв'язку. Обговорюються проблеми, що існують на шляху створення міжсупутникового оптичного зв'язку, а також визначення взаємного положення супутників та його відстеження. Визначаються наукові завдання для реалізації розробки оптимальної надійної системи керування міжсупутниковим зв'язком.

Ru Рассмотрено современное состояние научно-технических исследований и разработок малых космических аппаратов с использованием оптических систем связи. Обсуждаються проблемы существующие на пути создания межспутниковой оптической связи, а также определения взаиморасположения спутника и системы слежения. Определяються научные задачи для реализации разработки оптимальной надежной системы управления межспутниковыми связями.

\section{Introduction}

To have intersatellite communication, the dynamically moving object should be properly oriented. Once the recognition of one moving object with re-

\footnotetext{
${ }^{1}$ Iнституm VISHVANIKETAN, Індія
} 
spect to another is done then with proper stabilization, communication in between two satellites can be done. Recognition of desired satellite for information transmission is crucial and it University of Delhi is done through optics. Determining the location of the desired satellite using an optical system and keeping it on the optical axis is a critical factor in inter-satellite communications. The surveyed position determination techniques along with uncooperative object-based algorithms are categorized according to feature based or appearance-based models. Since optics is playing vital role here in inter-satellite communication, utilizing various sensors like LiDAR. Future research challenges in designing of optimal robust control system for such inte-rsatellite communication are very important.

1. Small Satellites Classification.

Most gatherings, databases, and surveys use mass-based classification [1, 2] ( Table 1).

Table 1.

Classification of Satellites based on mass in $\mathrm{kg}$.

\begin{tabular}{l|c|c|}
\hline \multicolumn{1}{|c|}{ Type of Satellite } & Surveys & Symposium \\
\hline Microsatellites & $100-10$ & $120-20$ \\
NanoSatellites & $10-1$ & $20-4$ \\
Pico Satellites & $1-0,1$ & $1-0,1$ \\
Cube Sat & & $4-1$
\end{tabular}

Providing value to customer for minimum cost in shortest period with minimum waste is worth to have constellation of satellites. After $2-4$ years each satellite in constellation should be renewed, thereby assuring that the operator will always have an enhanced low risk service that receives ongoing technological improvements.

Necessity of inter - satellite communication of Micro and Nano satellites. Nanosatellite constellations are therefore systems in which the concepts of obsolescence or useful life are no longer an issue. Because nano satellites have modular nature and low-cost, small satellites are too popular and suitable for formation of flying mission [3]. One of the significant parameters for satellite mission is the application. Smallsats have represent a new paradigm in the satellite industry. Some of important applications [4] of small satellites are: Earth observation; Earth observation communication and internet of things; geolocation and logistics; signal monitoring; scientific application.

2. Design Approach for Attitude Control.

Situational awareness (SA), space-based communication and imagery-based intelligence are the core drivers for market demand [5]. This is due to firstly, technology development in optical imaging, radio frequency interference (RFI), spectrum usage, optical communication on various platforms, miniaturization of propulsion systems and so on. Secondly low-cost approaches 
and infrastructure development results into growing market demand. The global consultancy Euroconsult predicts that, whereas fewer than 700 smallsats were launched from 2006-2015, up to 3,600 smallsats are likely to be launched in the coming decade for a variety of missions. This number could reach well over 10,000 if even a fraction of the planned broadband constellations is deployed [5].

2.1. Sensors and actuators. Sun sensors and magnetometers are the most generally used sensor type inside all pico-and nanosatellites. Angular rate measurement is also observed to be a very commonly used method for attitude control directly. As micro-electrical mechanical system (MEMS) gyroscopes, with minimum power utilization and low cost are widely used. Aside from position detection, the angular rate measurements are additionally utilized for attitude stabilization as well. An alternate sensor giving vector estimations - yet less regularly utilized than Sun sensors or magnetometers - is an Earth skyline sensor. Since the availability of wide range visible cameras, IR cameras, Light Detection and ranging (LiDAR) etc. are also observed in navigation in small satellites. In active stabilization reaction wheels, momentum wheels or fly wheels are observed as 40\% [1]. For highly pointing accuracy to develop a link between two small objects, efficient sensors with precise actuators with reduced cost is proved to be essential approach in satellite communication. Reduced form of reaction wheels, optical equipment for navigation, miniaturized from gyros and so on result into small satellites capable of higher accuracy attitude orientation.

2.2. Control System with Integrated Solution. Noticeable trend observed in small satellite communication is about to use highly efficient software with various algorithms to include all the miniaturized actuators and sensors integrated and furthermore processing unit which runs the control software. Various controllers like Proportional +Integral +Derivative (PID), Linear Quadratic Controller (LQC), and Fuzzy Logic Controllers (FLC) with modified versions of highly efficient and accurate algorithms also proved to be one of the designing approaches in attitude orientation.

2.3. Position Determination Through Optics and Uncooperative Objects based Algorithms. To perform autonomous relative navigation, spacecraft relies on technologies like Radio Frequency (RF), Guidance, Navigation and Control (GNC) systems based or electro optical (EO) sensors. Use of specific technology depends on field of application in terms of intersatellite distance and spacecrafts used are in cooperative mode or not. For extremely large distances i.e. from few hundred kilometers to few hundreds of meters differential GPS approach [6] is given for LOS and range measurement with 3 attitude states or Degree of Freedom (DOF). This approach is demonstrated in PRISMA mission as Spaceborne Autonomous Formation Flying Experiment (SAFE) [7]. In Orbital Express (OE) mission [8] the range detection and LOS of uncooperative spacecraft can be estimated with 
passive camera and laser range finder with 6 DOF (3 for rigid rotation plus 3 for translation). For close proximity with narrower distances about 100 meters with full 6 DOF pose, GPS based heavy antennas with high power requirements and suffering from multi path effects can put a limitation. Hence optics-based technology such as monocular technique or 3D technique with active LiDAR or passive supervision cameras can be used to detect position of target. These algorithms are categorized into two sections:

- Feature Based Methods:

Position estimation can be done from extracted features of 3D images such as line, co-linear points, spheres, cylinders, multiple types of geometric features, multiple cues and so on. Various algorithms based on feature-based technique are summarized as: 1) Template Matching (TM) algorithm exploited for pose determination in various ways. This kind of algorithm is used for searching specific features in 2D dataset (monocular image) [9] or 3D data set [10] (point cloud or range image). 2) Bounded Hough Transform (BHT) used the approach of voxel occupancy. 3) Nonlinear or iterative techniques with monocular sensors. 4) Algorithms like SoftPOSIT exclusively for the pose determining process as pose tracking step.

- Appearance Based Methods:

"Interpretation through Synthesis" type approach can be used in appearancebased type of methods. Variation in gray level from obtained training set of parameters and control mode of shape can pose determination of 2D images can be done. Various algorithms included in appearance-based method can be listed as: 1) 2D data (no longer LiDAR) using Adaptive Appearance Model (AAM) can be used for position determination. 2) For 3D dataset use of Principle Component Analysis (PCA) can also be used as appearancebased method. Searching of iterative features of 2D and 3D dataset based on TM [11] is always be used in position determination. Comparative analysis of Feature Based and Appearance Based Approach shown, that TM based approach and the SoftPOSIT algorithm is suitable for both acquisition and tracking. Similarly, feature based approach is more suitable as compared to appearance-based approach for position detection. In terms of position estimation accuracy both active and passive technologies give promising and comparable results but compared to passive sensors LIDAR have fundamental advantages in terms of level of autonomy and capability to differentiate target from background. Hence 3D model-based algorithms and focusing on LIDAR is more suitable for object navigation.

2.4. Position Determination Architecture. By adding the blocks like Acquisition to Tracking, Position Refinement and Autonomous Failure Detection Position Determination architecture can be modified. For autonomous position initialization and tracking step, Iterative Closest Point (ICP) based robust algorithm can be used [12].

2.5. Position Acquisition and Tracking: 
For position acquisition various approaches to use can be listed as: 1) 3D on-line Template Matching; 2) 3D on-line Fast Template Matching; 3) 3D PCAbased on-line Template Matching.

Position Tracking: Customized ICP algorithm with added ICP failure and prediction for coarse tuning of acquisition.

Accuracy level of Transition from Acquisition to Tracking can be achieved by ensuring safe transition from acquisition to tracking with modification of ICP based algorithm.

3. Light Detection and Ranging - LIDAR.

The term LIDAR is used to indicate a large variety of sensors that are basically able to measure distances by illuminating a target with a laser and analysing the backscattered radiation. The main components of a LIDAR system are the laser source (operating in the ultraviolet, visible and IR regions of the electromagnetic spectrum), the optics, the detector and the control electronics. Space LIDAR systems with a mass of $2 \ldots 15 \mathrm{~kg}$, operational range $10 \ldots 30000 \mathrm{~m}$, accuracy $0,01 \ldots 2 \mathrm{~m}, 40^{\circ}$ Field of View have been developed.

4. Control System Design.

PID controllers used in attitude control of spacecrafts with various algorithms improve the system performance. In autotuned controllers, 97\% PID algorithms are used in various applications. Idea of classical controller theory used in angle control $[13,14]$ is illustrated to improve the system performance. With certain limitations of classical control theory, robust control theory is developed to improve the system performance for various system uncertainties. Different view angles and complete derived expressions about the $\mathrm{H} \infty$ theory can be initiated in $[15,16]$. Despite quick development in control equipment, the Proportional - Integral - Derivative (PID) controller remains the pillar in process ventures presented a robust PID controller for tracking the satellite and attitude control. PID controller with nonlinear $\mathrm{H} \infty$ control certainly exhibits advantages for tracking a space shuttle under external disturbances. Combination of dynamic inversion and $\mathrm{H} \infty$ loop shaping for the UAV use in nonlinear PID controller shows significant robustness and improved performance. In orbital servicing capturing and refueling the inoperative spacecraft is one of the challenging missions. Using latest nonlinear attitude observers and attitude determination algorithms it is argued [17] that unconstrained methods with observers yield into better result as compared to constrained attitude observers. Static determination methods are more computationally demanding due to their optimization-based nature compared to other algorithms of attitude estimation. This has made the study of modern algorithms more appealing to the scientific community, such as Kalman filters and observers of attitude. This offer designers an inviting alternative to adding new sensors or upgrading existing ones. Luenberger observer gives the focus 
on the predictor-corrector structure. Feedforward control of nonlinear controller with Leunberger observer using least square estimation described in[18] used for attitude control for large slew maneuvers.

\section{Conclusion}

Literature review on small satellites, various applications of small satellites, design approaches used in small satellites, various attitude parameters, and various control system design are reviewed. Position determination of a moving object through optics as LiDAR is also studied. From the reviewed literature following research gaps can be noted.

For satellite position determination, optical based system like LiDAR can improve the operation required for Inter-Satellite communication.

For attitude stabilization of small satellites accuracy should be improved using PID controller with modified algorithm.

Suitable attitude stabilization method should be selected for precise control.

Proper selection of sensors and actuators gives the better accuracy.

\section{References}

1. J. Bouwmeester and J. Guo, "Survey of worldwide pico- and nanosatellite missions, distributions and subsystem technology," Acta Astronaut., vol. 67, no. 7-8, pp. 854-862, 2010.

2. M. Cho, M. Hirokazu, and F. Graziani, "Introduction to lean satellite and ISO standard for lean satellite," RAST 2015 - Proc. 7th Int. Conf. Recent Adv. Sp. Technol., pp. 789-792, 2015.

3. S. Bandyopadhyay, G. P. Subramanian, R. Foust, D. Morgan, S. J. Chung, and F. Y. Hadaegh, "A review of impending small satellite formation flying missions," 53rd AIAA Aerosp. Sci. Meet., pp. 1-17, 2015.

4. A. Narayanasamy, Y. A. Ahmad, and M. Othman, "Nanosatellites constellation as an IoT communication platform for near equatorial countries," IOP Conf. Ser. Mater. Sci. Eng., vol. 260, no. 1, 2017.

5. B. Lal et al., "Global Trends in Small Satellites," p. 400, 2017.

6. A. Renga, M. Grassi, and U. Tancredi, "Relative Navigation in LEO by Carrier-Phase Differential GPS with Intersatellite Ranging Augmentation," vol. 2013, 2013.

7. S. Damico, J. S. Ardaens, and S. De Florio, "Autonomous formation flying based on GPS - PRISMA flight results," Acta Astronaut., vol. 82, no. 1, pp. 69-79, 2013.

8. H. Benninghoff, T. Tzschichholz, and G. Gaias, "A Far Range Image Processing Method for Autonomous Tracking of an Uncooperative Target A 
FAR RANGE IMAGE PROCESSING METHOD FOR AUTONOMOUS TRACKING OF," no. January, 2013.

9. C. Reinbacher, M. Rüther, and H. Bischof, "Pose estimation of known objects by efficient silhouette matching," Proc. - Int. Conf. Pattern Recognit., pp. 1080-1083, 2010.

10. R. Opromolla, G. Fasano, G. Rufino, and M. Grassi, "A model-based 3D template matching technique for pose acquisition of an uncooperative space object," Sensors (Switzerland), vol. 15, no. 3, pp. 6360-6382, 2015.

11. R. C. Gonzalez, R. E. Woods, and P. Hall, Digital Image Processing. .

12. R. Opromolla, G. Fasano, G. Rufino, M. Grassi, O. Servicing, and A. D. Removal, "Autonomous Pose Initialization and Tracking," no. January, pp. 1-11, 2015.

13. F. A. Warsi et al., "Yaw, Pitch and Roll controller design for fixed-wing UAV under uncertainty and perturbed condition," Proc. - 2014 IEEE 10th Int. Colloq. Signal Process. Its Appl. CSPA 2014, pp. 151-156, 2014.

14. A. Prach, "A lateral autopilot for a tactical UAV," UDC 619.7, 2010.

15. M.-C. Tsai and D.-W. Gu, "Robust and Optimal Control Robust and Optimal," Gbvde, vol. 40, p. 586, 2014.

16. D. Before, T. Negotiations, N. Via, and N. Communication, "Essentials of Essentials of," no. March, 2008.

17. N. Madinehi, "Rigid Body Attityde Estimation: An overview and comparative study," pp. 1-152, 2013.

18. M. A. Cooper and P. T. Heidlauf, "Nonlinear Feed Forward Control of a Perturbed Satellite using Extended Least Squares Adaptation and a Luenberger Observer,” J. Aeronaut. Aerosp. Eng., vol. 07, no. 01, 2018. 